\title{
Factors Associated with the Decision to Obtain an HIV Test among Chinese/Chinese American Community College Women in Northern California
}

\author{
Sang Leng Trieu ${ }^{1,3}$, Naomi N. Modeste ${ }^{1}$, Helen Hopp Marshak ${ }^{1}$, Michael A. Males ${ }^{2}$, \\ and Sally I. Bratton ${ }^{3}$ \\ ${ }^{1}$ Loma Linda University, ${ }^{2}$ Center on Juvenile and Criminal Justice, and ${ }^{3}$ Ohlone College
}

\begin{abstract}
HIV testing and counseling is the cornerstone of a comprehensive approach to HIV prevention and education. This article examines reasons for and barriers to obtaining an HIV test among 230 Chinese/Chinese American college students. Using Health Belief Model constructs, a cross-sectional study was administered at four California community college campuses. The self-report survey results indicated that $30 \%$ of respondents have obtained HIV testing. The most common reasons for testing were "just to find out" (73\%), "having had unprotected sexual intercourse" (63\%), and "having had sex with a new partner" (57\%). Among those who were never tested, low levels of perceived susceptibility (66\%) and lack of knowledge on testing sites (36\%) were the most common barriers. Multiple unconditional logistic regression analyses revealed age, ethnic identity, lack of condom use during last intercourse, lower perceived barriers, and higher self-efficacy as significant predictors of HIV testing history. Emphasizing these factors in HIV education campaigns will likely increase testing rates within this population.
\end{abstract}

(c) 2008 Californian Journal of Health Promotion. All rights reserved.

Keywords: HIV testing, Chinese, college students, reasons for testing

\section{Introduction}

HIV testing and counseling is considered the cornerstone of a comprehensive approach to HIV prevention and education. Knowledge of serostatus is one of the specific objectives of the Healthy People 2010 "prevention of HIV infection" indicators (U.S. Department of Health and Human Services, 2000). Increasing the number of HIV-positive college students who know their serostatus among is also identified as a high-priority objective in Healthy Campus 2010, a set of national health objectives that are a by-product of Healthy People 2010, specifically outlined for the college population (American College Health Association, 2002). In a study on the impact of HIV test counseling on college students' sexual beliefs and behaviors, researchers concluded that testing could serve the dual purpose of HIV prevention education, as well as determining college students' HIV status (Mattson, 2002).

\section{Research Purpose}

The purpose of this research was to examine factors associated with the decision to obtain an HIV test among Chinese/Chinese American community college women. Research is needed to understand predictors of HIV risk and HIV testing in order to examine the reasons Chinese/Chinese American college women choose to get tested or to avoid testing. The recent shift in CDC's national policy to place more emphasis on HIV testing as a central focus of HIV prevention requires improved understanding of how individuals arrive at the decision to take an HIV test (Morrill \& Noland, 2006).

The Health Belief Model (HBM) was used as the theoretical framework for this study, as it has demonstrated to be useful for predicting HIV preventive behavior (Steers, Elliot, Nemiro, Ditman, \& Oskamp, 1996). The HBM is a psychological model used to explain, predict, 
and influence health behaviors, in which a person believes he or she: (1) is susceptible to the disease (perceived susceptibility); (2) perceives the disease to be moderately or severely impacting one's life (perceived seriousness); (3) adopts recommended behaviors that could reduce the risk or seriousness of impact (perceived benefits); and (4) will not be obstructed by factors such as cost, pain, or stigma (perceived barriers). The construct, selfefficacy, refers to the confidence in one's ability to successfully perform a certain behavior. This construct was added to the HBM model to better address habitual unhealthy behaviors (Glanz, Rimer, \& Lewis, 2002).

According to Yep (1993) and Cooper and colleagues (2001), the Health Belief Model has shown greater utility in examining screening behavior for use among Asians than any other model because of the positive relationship between many of the constructs and the desired behavior. The model has been used in previous API studies on HIV prevention as well as other health behavioral studies. The HBM was previously used to examine screening behaviors among Chinese American women, including cultural barrier factors for obtaining clinical breast exams, mammographies, and cervical cancer screenings, but not to explain or predict HIV testing (Lee-Lin, Menon, Pett, Nail, Lee, \& Mooney, 2007; Yu \& Wu, 2005). The HBM was selected for this research study because HIV testing is an important screening behavior, particularly for secondary prevention, and is the best model to identify predictors of screening behaviors.

Asian Pacific Islanders (APIs) constitute 1\% of the total AIDS cases reported in the US. Of these API cases, $13 \%$ are attributed to API women. This figure may be inaccurate due to underreporting and lack of detailed HIV surveillance data for this group (UCSF, 2003). Recent statistics also indicate that from 20012004, APIs experienced increasing incidences of HIV/AIDS infection in both genders, while other ethnic groups reported declines (CDC, 2006). Very little is known about HIV infection patterns among API women, though heterosexual contact is the primary risk factor, accounting for approximately $75 \%$ of all such cases (Zaidi et al., 2005; Wortley, Metler, $\mathrm{Hu}, \&$ Fleming, 2000). Furthermore, $18 \%$ of cumulative cases and $42 \%$ of new AIDS cases among API women are categorized as "risk not identified," higher than any other ethnic group (Darbes, Kennedy, Peersman, Zohrabyan, \& Rutherford, 2002).

For the purpose of this paper, the term "Chinese" refers to an individual who claims Chinese ancestry as her ethnic identity, while the latter term "Chinese American" refers to an individual who claims a dual ethnic identity composed of both Chinese and American heritage. Both terms are used in order to capture the full spectrum of ethnic identity and are mutually exclusive.

Chinese account for $12 \%$ of cumulative AIDS incidences of APIs in the US. However, little is known about HIV prevention, including HIV testing rates for Chinese/Chinese American women, because data are aggregated under an API umbrella and rarely broken down into specific ethnic groups. The limited number of studies conducted on API women addressing HIV-related sexual risk assessments, perceived susceptibility to HIV, and partner characteristics on condom negotiations, show that there is a critical need to direct more attention to this population, with specific focus on single ethnic groups (Chin, 1999; Cooper, Loue, \& Lloyd, 2001; Jemmott, Maula, \& Bush, 1999; Lam \& Barnhart, 2006).

Although APIs comprise the largest proportion of anonymous HIV test site clients, they also reported the lowest testing rates of any ethnic group $333.3 \%$ of Asian women compared to $33.6 \%$ of White women, $45.4 \%$ of Hispanic women, and $52.4 \%$ of Black women) (Zaidi et al., 2005). One study conducted in San Diego found that $18 \%$ of API respondents reported having been screened for HIV (Cooper et al., 2001). Moreover, data obtained from the National Longitudinal Study of Adolescent Health reported that just $10.8 \%$ of young API adults (ages 18-26) tested for HIV, compared to $18.7 \%$ of Whites (Nguyen, Ford, Kaufman, Leone, Suchindran, \& Miller, 2006). 
A wide range of estimates are used to describe the HIV testing rates on national and statewide levels. The 2006 National Health Interview Survey reported that $40.3 \%$ of women of all ethnic and racial backgrounds ages 18-24 have been tested (US DHHS, 2006). The 2006 California Health Interview Study (CHIS) reported that $61.1 \%$ of respondents who were Chinese obtained testing. It is important to bear in mind that this rate reflects all genders, ages, and sexual orientations of those who identified as Chinese in CHIS, another example of lack of disaggregated data (Holtby, Zahnd, McCain, Chia, \& Kurata, 2006). Moreover, approximately $24 \%$ of 20-29 year olds of all ethnic and racial backgrounds obtained testing at publicly funded sites in the state, as reported in the 2004 California HIV Counseling and Testing Annual Report.

Reasons for obtaining an HIV test are varied and have also changed over the course of the epidemic. The influence of peers was found to be a significant motivating factor for students who decided to test (Anastasi, Sawyer, \& Pinciaro, 1999). The use of peer outreach programs to encourage testing may help destigmatize the process, empower students to take responsibility for their own health, and provide support for other students considering getting an HIV test. A survey of students attending a private, church-affiliated college found the primary reasons for testing to be routine checkups, blood donation, and unprotected sex (Opt \& Loffredo, 2004). Reports from the National Health Interview Surveys showed "part of a routine medical check up," pregnancy, and "wanted to find out if infected or not" were the common reasons adults seek testing (Inungu, Beach, Cook, \& Lamerato, 2005).

Assessing knowledge, attitudes, and selfefficacy towards HIV/AIDS is essential in understanding how to build effective prevention programs. For API college students, however, research in this area has shown inconsistent results. A recent study on heterosexual API college students showed that respondents lack basic information about transmission, risk, and prevention of HIV infection (So, Wong, \&
DeLeon, 2005). Among a cohort of community college students in Orange County, California, Asian students demonstrated the lowest level of knowledge and concern about HIV compared to other ethnic groups (Shapiro et al., 1999). In the first study of HIV/AIDS knowledge and sexual behaviors among Taiwanese American college students, Lin, Simoni, and Zemon (2005) found that greater self-efficacy was significantly associated with fewer sexual partners, lower sexual intercourse frequency, and greater consistency of condom use.

APIs in the US are a heterogeneous group, representing more than 50 countries and speaking more than 100 languages and dialects. The lack of disaggregated data among the API population provides insufficient specific information about the effects of the HIV epidemic on Chinese Americans. Since the first arrivals 150 years ago, there are approximately 2.4 million Chinese in the US, comprising the largest API ethnic group, or one-fourth of the total API population (U.S. Census, 2000). The majority $(63 \%)$ are foreign-born, primarily emigrating from mainland China, Hong Kong, and Taiwan. Many others have emigrated from Southeast Asia, from countries such as Singapore, Malaysia, and Vietnam, selfidentifying as Chinese, based on their origins and cultural roots. California is home to $40 \%$ of all Chinese Americans.

\section{Methods}

This research study used an exploratory, descriptive, cross-sectional survey design that included mixed methods to investigate factors that influenced the decision to obtain an HIV test among Chinese American students attending four community colleges in Northern California. The study was conducted in two phases using qualitative (focus groups) and quantitative (webbased and paper-pencil questionnaire) methods, and was based on constructs of the Health Belief Model. Data derived from the focus groups was used to assist in the development of the questionnaire that was used in the quantitative phase. The questionnaire consisted of seven sections totaling 56 items. Five scales were used to examine constructs of the HBM: a 13-item 
scale to calculate HIV knowledge, a six-item scale to assess perceived susceptibility, a threeitem scale to measure perceived seriousness, a 13-item scale to assess perceived benefits and barriers, and a three-item scale to measure selfefficacy. The Suinn-Lew Asian Self-Identity Acculturation (SL-ASIA) scale is a 21-item tool that was included in the survey to measure acculturation levels and further explores the impact of cultural factors on sexual behavior, including HIV testing. Acculturation was defined as "a process that can occur when two or more cultures interact together" or a "continuum of cultural affiliation and identity" (Suinn, 1995, pg. 6; Estrada \& Estrada, 2002, pg. 2).

Internal reliability analysis was conducted on all of the HBM scales. Cronbach's alpha scores were moderately high for four of the constructs (susceptibility $=.78$; seriousness $=.84$; benefits $=.73$; barriers $=.74$ ) and modest for selfefficacy (.66). The SL-ASIA Acculturation Scale had a high internal reliability score of .91. Average scores were used for all HBM and acculturation variables with no items dropped.

\section{Measures}

HIV testing status, a dichotomous variable categorized as either a history of testing or no testing, served as the dependent variable. Independent variables included the six constructs of the HBM as discussed above, current or previous relationship status (casual versus committed), partner communication about HIV testing/serostatus, sexual history and behavior such as age of sexual debut and number of sexual partners in the last year, and demographic variables such as age, ethnic identity, and place of birth.

HIV knowledge was assessed using DiClemente's AIDS Knowledge scale, a 13-item tool with a dichotomous response option of "yes" or "no" to various statements on prevention and transmission of the AIDS virus (DiClemente, Brown, Beausoleil, \& Ludico, 1993). Perceived susceptibility of HIV infection was measured with a six-item instrument using a four-point Likert scale, a previous adaptation of a subscale of the HBM model (Lux \& Petosa, 1994), with a minor change in an adjective in the middle range of agreement, from "mildly" to "somewhat." Perceived susceptibility was measured using statements such as "People like me do not get HIV infections" and "I am not worried that I might get an HIV infection" with reverse coding. The perceived seriousness scale was adapted from the Risk Behavior Diagnosis Scale containing three items using a five-point Likert scale (Witte, McKeon, Cameron, \& Berkowitz, 1995). Assessments of perceived benefits and perceived barriers were combined into a 13-item tool using a five-point Likert scale. Reverse coding occurred for perceived barrier items so that higher scores indicate more perceived barriers to testing. Self-efficacy in obtaining an HIV test was measured with a three-item tool using a four-point Likert scale with reverse coding so that higher scores indicate greater self-efficacy, which was adapted from a self-efficacy scale for condom use negotiation among adolescents (Rotheram-Borus et al., 1997).

\section{Data Collection}

Participants for the focus groups were recruited through a number of ways, including posting flyers around campus, posting a flyer and signup sheet at the patient check-in encounter at the student health center, and recruiting through a snowball sampling procedure through participants who had already volunteered their participation. Focus group topics included how participants defined sex, inquiring about their dating experiences, the ethnicity of their partners, whether they have been tested for HIV, and the reasons why they sought testing.

Participants for the quantitative survey were selected using a convenience sampling technique based on the following criteria: (a) selfidentified Chinese or Chinese American; (b) heterosexual female; (c) 18-24 years old; (d) student at one of the four participating community colleges; and (e) history of sexual intercourse. Recruitment took place at student health centers, HIV testing clinics, ethnic student clubs, and high traffic areas using flyers, postcards, direct solicitations, and classroom presentations. For one campus, email invitations to participate were also sent to students who met the ethnic, age, and gender criteria. The study 
was also posted on one college's website and one social networking internet portal (Myspace.com). To improve the participation rate, incentives including a random drawing for an iPod, $\$ 100$ cash, or a one-term campus parking permit were offered. Participation in the study was on a voluntary basis. Loma Linda University's Institutional Review Board approved the research study.

The researchers were representative of the targeted population in terms of age, gender, and ethnicity. Recruitment was self selected for the online version of the survey. For the paper version, recruitment began by identifying individuals who appeared to be Asian, followed by a short screening using the inclusion criteria. Upon meeting the criteria, participants were given a questionnaire to complete on the spot, while researchers stood nearby to respond to questions that may arise. Completed surveys were collected and inserted in a sealed envelope.

\section{Statistical Analysis}

Descriptive statistics were calculated for demographic information and sexual behavior. Pearson chi-square tests were conducted to assess associations between individual knowledge items of HIV and testing status, and an independent samples t-test was used to compare the mean knowledge scores of those who had a history of HIV testing and those who had never been tested. Scores for constructs of the HBM model, including perceived susceptibility, perceived seriousness, perceived benefits, perceived barriers, and self-efficacy, were also compared between those who had been tested versus those who had not tested using independent samples t-tests. Frequencies were calculated to examine the most frequent reasons indicated for obtaining an HIV test and barriers for those who have never tested.

A multiple unconditional logistic regression was used to examine which variables were associated with whether participants have had an HIV test using a hierarchical model. The first group included age, place of primary and secondary education, ethnic identity, place of birth, relationship status, and condom use during last sexual intercourse. The second group examined the five HBM variables and the third group tested the predictability of acculturation. The groups of variables were entered simultaneously.

\section{Results}

\section{Focus Group}

Focus groups were conducted at two campuses with a total of 12 participants, whose mean age was 20 years. Sexual history, in regard to the number of sexual partners, closely resembled the findings from the primary study. Focus group participants had a mean number of sexual partners in the last year of 1.42, and mean number of lifetime sexual partners was 2.75. A total of $50 \%$ of the focus group participants felt "very concerned" about HIV infection, as demonstrated through their high testing rate of $57 \%$, which was almost twice the rate of survey participants.

\section{Participant Characteristics}

The self-report survey study included a sample of 230 Chinese/Chinese American college heterosexual females who have had sexual intercourse, operationalized as oral, vaginal, or anal penetration. Even though the study focused on one specific ethnic group, demographic data illustrates the heterogeneity of the population as it relates to identity, country of origin, and sexual practices (Table 1). Slightly more than half $(56 \%)$ of the respondents were Americanborn, while the remaining were born in China, Hong Kong, Taiwan, or Southeast Asia. The respondents' dating patterns were fairly homogeneous, with an overwhelming majority having dated or were dating only Asians/Asian Americans, and more than half with only Chinese/Chinese Americans. The sample consisted of a moderately acculturated group with a mean total score of $2.8(\mathrm{SD}=.63)$ on a five-point Likert scale. Those born in the US had a mean score of $3.17(\mathrm{SD}=.48)$, while scores for those born abroad ranged from 2.23 (SD = $.39)$ to $2.49(\mathrm{SD}=.36)(\mathrm{p}<.001)$. There were also marked differences in acculturation patterns in regards to ethnic identity. The respondents who identified themselves as Chinese Americans or of Chinese mixed heritage scored higher, 3.14 $(\mathrm{SD}=.47)$ versus $2.40(\mathrm{SD}=.55)(\mathrm{p}<.001)$, 
compared to those who identified themselves as Chinese, Taiwanese, or Taiwanese Americans.

Overall, the respondents reported a relatively conservative number of sexual partners, with a mean of 1.32 partners in the last year and a mean of 2.86 lifetime partners. Respondents (56\%) reported using condoms as their primary method of birth control, and $22 \%$ reported oral contraceptives. The third most frequent method did not involve the use of any contraception (10\%), which may partially explain the relatively high rate of emergency contraceptive use $(38 \%)$, which is more than six times the reported national usage rates of six percent found among women of ages 18-49 (Kaiser Family Foundation, 2005).

\section{HIV Testing History}

Of the Chinese/Chinese American community college students in this sample, $29.9 \%$ reported a history of HIV testing, while $70.1 \%$ had never been tested. Among those who had tested, the majority $(62.1 \%)$ had one test in their lifetime, and about one-fifth $(22.7 \%)$ had two tests (mean $=1.57 ; \mathrm{SD}=.89)$. Nearly half $(48.5 \%)$ of these tested respondents received their most recent
HIV test at community or public clinics, followed by their private doctor $(25 \%)$, and the campus student health center $(19.1 \%)$.

\section{HIV Knowledge}

As Table 2 illustrates, the total mean score for all participants was $83.4 \%(\mathrm{SD}=13.45)$. There were significant differences between those who have tested and those who have never tested when comparing mean percent correct, $(88.2 \%$ versus $81.8 \% ; \mathrm{p}=.001)$. Participants who have never tested scored consistently lower on all 13 questions, with statistically significant lower scores on the following four items: "A person can get AIDS from using public toilet seats;" "A person can get AIDS from donating blood;" "People can reduce their chances of becoming infected with the AIDS virus by not having any kind of sexual intercourse (being abstinent);" and "A person can get AIDS from being bitten by mosquitoes/insects." The following three items had the lowest scores: "A person can get AIDS from donating blood," "A person can get AIDS from having a blood test," and "A person can get AIDS from being bitten by mosquitoes/insects."

Table 3.

Means and Standard Deviations of the Health Belief Model Variables between Tested versus Not Tested

\begin{tabular}{|c|c|c|c|c|c|c|c|}
\hline & \multicolumn{2}{|c|}{ Total } & \multicolumn{2}{|r|}{ Tested } & \multicolumn{2}{|c|}{ Never Tested } & \multirow[b]{2}{*}{$p$ Value } \\
\hline Variable & $\mathrm{N}$ & $\begin{array}{r}\text { Mean } \\
\text { (SD) }\end{array}$ & $\mathrm{N}$ & $\begin{array}{r}\text { Mean } \\
\text { (SD) }\end{array}$ & $\mathrm{N}$ & $\begin{array}{r}\text { Mean } \\
\text { (SD) }\end{array}$ & \\
\hline $\begin{array}{l}\text { Perceived } \\
\text { Susceptibility }^{\mathrm{a}}\end{array}$ & 224 & $\begin{array}{r}3.24 \\
(0.73)\end{array}$ & 67 & $3.40(0.69)$ & 157 & $\begin{array}{r}3.17 \\
(0.74)\end{array}$ & .920 \\
\hline $\begin{array}{l}\text { Perceived } \\
\text { Seriousness }\end{array}$ & 224 & $\begin{array}{r}4.35 \\
(1.04) \\
\end{array}$ & 67 & $4.64(0.86)$ & 157 & $\begin{array}{r}4.23 \\
(1.09) \\
\end{array}$ & $.001 *$ \\
\hline Perceived Benefits ${ }^{\mathrm{c}}$ & 224 & $\begin{array}{r}4.63 \\
(0.50) \\
\end{array}$ & 67 & $4.77(0.33)$ & 157 & $\begin{array}{r}4.57 \\
(0.55) \\
\end{array}$ & $.0001 *$ \\
\hline Perceived Barriers ${ }^{\mathrm{d}}$ & 223 & $\begin{array}{r}2.03 \\
(0.87)\end{array}$ & 66 & $1.65(0.71)$ & 157 & $\begin{array}{r}2.19 \\
(0.88)\end{array}$ & .093 \\
\hline Self-Efficacy ${ }^{\mathrm{e}}$ & 222 & $\begin{array}{r}3.09 \\
(0.69)\end{array}$ & 66 & $3.59(0.54)$ & 156 & $\begin{array}{r}2.88 \\
(0.64)\end{array}$ & .091 \\
\hline
\end{tabular}

$* \mathrm{p}<.01$

Note. ${ }^{a}=6$ item scale using 4 point Likert Scale. ${ }^{\mathrm{b}}=3$ item scale using 5 point Likert Scale.

${ }^{c}=7$ item scale using 5 point Likert Scale. ${ }^{\mathrm{d}}=7$ item scale using 5 point Likert Scale.

${ }^{\mathrm{e}}=3$ item scale using 4 point Likert Scale. 


\section{HBM Measurements}

Respondents perceived a fairly high level of susceptibility to HIV (mean = 3.24) $($ Table 3$)$. Those who have been tested had a mean score of $3.40(\mathrm{SD}=.69)$ while those who have never tested had a mean score of $3.17(\mathrm{SD}=.74)$. Differences between the tested and not tested groups were statistically significant $(\mathrm{p}=.001)$, with higher perceived seriousness reported among those tested. More than half $(50.4 \%)$ marked "strongly disagree" with the statement, "I believe that HIV infection is severe." Significant differences were detected between those tested and not tested in perceived benefits of HIV testing ( $\mathrm{p}=.0001)$, such that there was greater perception of benefits reported by those who had been tested. The respondents who had ever tested scored higher than those who had never tested (3.59 compared to 2.88), though mean scores were not statistically significant $(\mathrm{p}$ $=.091$ ). The five scales were used in its original form without adaptation, and the survey instrument was pilot tested prior to administration.

\section{Reasons for and Barriers to Testing}

The most common reasons reported for obtaining an HIV test included "just to find out" (73.1\%); "had unprotected oral, vaginal, and/or anal sex" (62.7\%); and "had sex with a new partner" (56.7\%) (Table 4). Additionally, more than two-fifths of the respondents reported "time for a regular test" $(44.8 \%)$ and "health care provider or health educator recommended" $(41.8 \%)$. Among those who had never had an HIV test, the most frequent responses for not getting tested were, "I am at low risk for HIV infection" (42\%), "I am not sure where to go get tested" (36.3\%), and "I don't think I can get HIV" (24.2\%), while $33.8 \%$ reported no particular reason.

The participants responded differently to the online version versus the paper version of the questionnaire inquiring the reason(s) for deciding to get the last HIV test, despite the identical wording of the two versions. This was because with the online version of the question, the respondents were mechanically restricted from selecting more than one choice each for the "main reason" and the "secondary reason, if any." The paper version, however, had no such restriction. Thus, a number of participants that used the paper version selected more than one choice for the "main reason" and the "secondary reason, if any." Despite this difference between the two versions, a chi-square analysis found no significant difference in reasons for testing.

Table 4.

Reasons for and Barriers to HIV Testing

\begin{tabular}{|c|c|}
\hline Reasons for HIV Testing & $\%$ \\
\hline 1. Just to find out & 73.1 \\
\hline $\begin{array}{l}\text { 2. Had unprotected oral, vaginal, } \\
\text { and/or anal sex }\end{array}$ & 62.7 \\
\hline 3. Had sex with a new partner & 56.7 \\
\hline 4. Time for regular test & 44.8 \\
\hline $\begin{array}{l}\text { 5. Health care provider or health } \\
\text { educator recommended }\end{array}$ & 41.8 \\
\hline 6. Immigration requirement & 37.3 \\
\hline 7. To confirm previous test results & 35.8 \\
\hline 8. Asked by partner & 34.3 \\
\hline 9. Influenced by friends & 34.3 \\
\hline 10. Illness (STD or non-STD) & 32.8 \\
\hline 11. Had a partner with other STDs & 31.3 \\
\hline 12. Insurance requirement & 31.3 \\
\hline 13. Had/have an HIV-positive partner & 31.3 \\
\hline 14. As part of a research study & 29.9 \\
\hline Reasons for Not Testing & $\%$ \\
\hline 1. I am at low risk for HIV Infection & 66.2 \\
\hline 2. I am not sure where to go get tested & 36.3 \\
\hline 3. No particular reason & 33.8 \\
\hline 4. I don't know how the test is done & 28.7 \\
\hline 3. I don't think I can get HIV & 24.2 \\
\hline 5. Inconvenience & 17.8 \\
\hline 6. I don't worry about HIV & 17.2 \\
\hline 7. I am worried about confidentiality & 11.5 \\
\hline 8. I am afraid to learn the results & 7.6 \\
\hline
\end{tabular}




\section{Other Factors Influencing the Decision to Obtain an HIV Test}

Three sequential multiple unconditional logistic regression analyses were conducted, which revealed that a number of demographic and sexual behavior variables and two HBM constructs were significant factors in predicting whether participants had an HIV test. In each chunk of variables, demographic and sexual behavior variables were entered first (i.e., age, country of primary and secondary education, ethnic identity, place of birth, relationship status, and condom use during their last sexual intercourse), followed by the five HBM variables (i.e., perceived susceptibility, perceived seriousness, perceived benefits, perceived barriers, self-efficacy), and lastly, acculturation. Variables that had more than two categorical response choices were recoded into dichotomized variables.

The first multiple unconditional logistic regression analysis, with the overall model being significant, indicated that age $(\mathrm{OR}=1.43$, $95 \% \mathrm{CI}=1.19,1.73 \mathrm{p}<.001)$, ethnic identity dichotomized as Chinese American/Taiwanese American/mixed Chinese heritage versus Chinese/Taiwanese $(\mathrm{OR}=.37,95 \% \mathrm{CI}=.143$, $.948, \mathrm{p}=.038$ ), and lack of condom use during last sexual intercourse $(\mathrm{OR}=.39,95 \% \mathrm{CI}=.2$, $.77, \mathrm{p}=.007)$ were significant predictors of having been HIV tested, accounting for $16 \%$ of the variance in testing. The second group of variables of the HBM model was significant, accounting for $34 \%$ of the variance or an additional $18 \%$ beyond the demographic variables. Self-efficacy $(\mathrm{OR}=4.86,95 \% \mathrm{CI}=$ $2.30,10.26, \mathrm{p}<.001)$ and perceived barriers $(\mathrm{OR}=.43,95 \% \mathrm{CI}=.24, .80, \mathrm{p}=.007)$ were significant predictors of testing, while the demographic and sexual health variables in the first group remained significant. The third group of variables examined if acculturation significantly predicted testing, and the overall model accounted for $35 \%$ of the variance, although acculturation alone was not significant as a unique predictive variable.

\section{Discussion}

This was one of the first studies to examine a disaggregated Asian Pacific Islander group's HIV testing behavior, specifically Chinese/Chinese American community college women, by assessing self-reported testing rates and exploring reasons for and barriers to testing in a socio-contextual manner. This study further disaggregated the Chinese ethnic identity into Chinese and Taiwanese ethnic groups. While Chinese and Taiwanese populations share similar language and cultural background, there are differences that exist in lifestyle and social background characteristics that warrant this additional disaggregation. For example, it has been shown that there are differences in the degree of exposure to Western culture for international students coming from China versus Taiwan (Wang \& Mallinckrodt, 2006).

Approximately $30 \%$ of students in this sample had a history of testing, citing the desire to learn one's serostatus, the engagement in unprotected sexual intercourse, and the acquisition of a new sex partner as the main reasons to seek testing. Low perception of susceptibility and uncertainty of testing sites were most frequently noted as reasons the majority of the respondents have never had an HIV test. After applying the Bonferroni adjustment, two of the five constructs of the HBM, namely perceived barriers and self-efficacy, were also significant predictors for history of HIV testing.

Of the participants in the two focus groups, $58 \%$ reported having been tested for HIV. They reported having had an overall positive experience, indicating that getting tested was the "smart" thing to do and that getting an HIV test was similar to being screened for other diseases. For respondents who have never tested, having a partner who was a virgin and thus with no perceived risks, lack of information about the availability of a non-invasive testing method, and fear of testing were cited as reasons why they did not seek testing.

Studies involving female students of all ethnic and racial backgrounds generally indicate an HIV testing rate in the $20 \%$ to $30 \%$ range. In a 
1999 study of the general student population at four community colleges in Orange County, California, 30\% reported previous testing (Shapiro, Radecki, Charchian, \& Josephson, 1999). A 2003 study at a California State campus showed that female students reported testing more often than their male counterparts, $24 \%$ compared to $19 \%$, respectively (Flannery \& Ellingson, 2003). A 2004 study conducted at two large southern California campuses reported that $21 \%$ of students sampled had been tested for HIV (Marelich \& Clark, 2004). Another 2004 study, conducted on an east coast campus, showed $23 \%$ of undergraduates with an HIV testing history, with higher rates as the years of college attendance increased (Opt et al., 2004). A study on a Southeastern campus reported that $20.1 \%$ have been previously tested, while $39.5 \%$ have asked their partner's HIV status (Hou, 2007). In contrast, the most recent study of the general college student population, conducted on a consortium of 13 community colleges in California, revealed an HIV testing rate of $44 \%$ for female students of all ethnic and racial backgrounds. However, it also revealed that API female students tested at a substantially lower rate of $31 \%$ (American College Health Association, 2007). This study showed similarly low testing rates of $30 \%$ for Chinese/Chinese American college students. The significantly lower HIV testing rate among Chinese/Chinese Americans and other APIs indicates that issues affecting access and utilization of HIV testing programs among these groups need to be better addressed.

\section{Implications}

The results of this study provide an understanding of attitudes and beliefs about HIV and HIV prevention, which has implications for the development of culturally appropriate health education programs. The reasons the participants indicated for obtaining testing in this study were markedly different from previous research on college students of all ethnic and racial groups. In previous research, some of the most common influential factors were external influences such as "friend/peer" and routine check-ups. Unprotected sex has also been cited as one of the primary reasons in a number of studies, a key recommendation for HIV screening by health care providers and CDC. In contrast, the most common reason cited among this study's population for obtaining an HIV testing was "just to find out."

The nebulous statement of "just to find out" likely masks other more specific reasons for testing, which remain hidden due to cultural pressures that inhibit open discussions of sexual topics, especially relating to HIV \& STDs, which are considered taboo. For example, sexrelated matters are often times communicated in signals and codes and often times in romanticized euphemisms. This is evidenced by a study examining condom negotiation strategies among heterosexual Asian and White college students, wherein researchers found that Asians of both genders, more than Whites, used verbalindirect strategies such as dropping hints as means of persuasion (Lam, Mak, Lindsay, \& Russell, 2004). The responses of "just to find out" seem to confirm API women's preference to engage in non-explicit and indirect approach to HIV related issues, likely for the similar reasons APIs prefer verbal-indirect strategies in condom use negotiations. Remaining sensitive to these and other cultural issues will aid healthcare providers in providing more effective HIV education and counseling.

After "just to find out," "engaging in unprotected sexual intercourse" and "having sex with a new partner" were the two subsequent most common reasons for testing in this study sample. Given that heterosexual contact is the main risk factor for HIV infection among API women, it is encouraging that such reasons cited reflect an increasing sense of personal responsibility when it comes to assessing HIV risk factors. Acquisition of a new sex partner may imply that Chinese/Chinese American college students are proactive in inquiring about sexual history, including serostatus, which increases the level of partner communication around such topics (Wenger, Linn, Epstein, \& Shapiro, 1991).

As for those who never had been tested, low perception of susceptibility to HIV infection was the most common reason cited (42\%), although perceived susceptibility scores for those who 
never tested were moderately high (3.17 on a 4 point Likert scale). A previous study on API women's perceived susceptibility to HIV revealed the fear of how one's family and community may react to an HIV positive person may influence the perception of susceptibility (Cooper et al., 2001). Thus, in Asian cultures, in which the importance of bringing honor and avoiding shame to the family is strongly upheld, individuals may not be as willing to seek HIV testing.

The lack of knowledge regarding testing facilities was the second most common reason indicated for not having ever been tested (36\%). This was an unanticipated finding, especially because the study was conducted on campuses located in the San Francisco Bay Area, which, as one of the epicenters of the HIV epidemic, has a relatively sophisticated public health system addressing HIV/AIDS issues. This lack of knowledge regarding testing facilities is a structural-level barrier, which campus student health centers have a pivotal role in helping to eliminate. College campuses have a responsibility to promote healthy behaviors and create environments that support health. As such, they are encouraged to play a proactive role in HIV prevention by offering testing and counseling services. Health promotion efforts on campuses can include social marketing campaigns to heighten awareness on the importance of testing, as well as providing better access to both on-campus and community-based testing services. The American College Health Association's guidelines on Standards of Practice for Health Promotion in Higher Education strongly encourage the formation of campus and community partnerships to advance health promotion initiatives.

There was an interesting array of "other" writein responses as to the reasons behind not having tested. "One completely loyal and clean partner," "not sure if the last check up I did included this test..." and "I don't do or get involved with people who may be at risk for HIV infection" were several of the responses to the question. A few participants expressed concerns about the use of needles, suggesting another area of misperception on the method of
HIV test administration, especially in light of low knowledge scores on certain items. Several students indicated their intention to test in the near future as part of write-in responses.

While knowledge of preventive health behavior, specifically HIV prevention behavior, does not always directly lead to safer sexual practices, HIV education must be considered a foundational component to a comprehensive approach to a culturally competent prevention program. It is alarming that, despite the passage of nearly three decades from the start of the HIV/AIDS epidemic, misperceptions such as transmission of HIV through mosquito bites or toilet seats still persist (CDC, 1999). Level of knowledge was only slightly better among participants in this study compared to Asian adults in the state. A statewide survey of California adults that assessed knowledge, attitudes, beliefs, and behaviors regarding HIV and AIDS in 2000 revealed that $22 \%$ of Asians believed that using public toilets could transmit HIV (12.1\% in this study responded incorrectly), and $43 \%$ believed that HIV could be contracted from a mosquito bite $(25.5 \%$ in this study missed this question). Low scores were also reported on items regarding transmission from donating blood (39\% responded correctly) and from having a blood test $(62 \%$ responded correctly). HIV education programs that directly address these high levels of misinformation and incorrect beliefs about transmission will increase people's knowledge around risk factors, and perhaps help to increase self-efficacy and eliminate perceived barriers to testing.

The mean age of sexual debut among participants in the sample was 16.97 , higher than other ethnic groups and previous research on this API population. A recent study comparing sexual behaviors of White and Chinese American females showed a 15.3 age of first sexual intercourse for Chinese American girls (Kuo \& St. Lawrence, 2006). Reasons for the older mean age found in this study may be due to the high number of international students represented in the sample. Anecdotally, during pre-screening for qualification for survey participation, recruiters noticed that the most frequent reason for disqualification was their 
virginity status. The later sexual debut of the sample population in this study may explain the lower number of sexual partners they have had in both the previous year and in their lifetime, since more than half of the study participants were of age 18 or 19 , and therefore had fewer sexually active years. The implications for older age of sexual debut among Chinese/Chinese Americans should be further examined to assess whether it serves as a protective factor in the reduction of sexually risky behavior.

Table 5

Results of Multiple Unconditional Logistic Regressions

\begin{tabular}{|l|r|r|r|r|}
\hline & \multirow{2}{*}{ Sig. } & \multirow{2}{*}{$\operatorname{Exp(B)}$} & \multicolumn{2}{|c|}{$\begin{array}{c}\text { 95.0\% C.I. for } \\
\text { EXP(B) }\end{array}$} \\
\hline Age & & & \multicolumn{1}{|c|}{ Lower } & \multicolumn{1}{|c|}{ Upper } \\
\hline Ethnic Identity & .016 & .184 & .047 & .726 \\
\hline Condom Use & .002 & .168 & .056 & .506 \\
\hline Self-Efficacy & .000 & 5.067 & 2.345 & 10.950 \\
\hline $\begin{array}{l}\text { Perceived } \\
\text { Barriers }\end{array}$ & .014 & .463 & .252 & .853 \\
\hline Acculturation & .040 & 3.415 & 1.058 & 11.023 \\
\hline
\end{tabular}

The variables that emerged as significant correlates to HIV testing based on regression analyses include: older age (21-24), ethnic identity (Chinese American/Taiwanese American identification as indication of biculturalism and/or assimilation), lack of condom use during last sexual intercourse, lower perceived barriers, and higher self-efficacy (Table 5). API cultural identity has been found to be an asset in shaping sexual behavior (Advocates for Youth, 2007). Thus, addressing such factors may help to shape positive messages that encourage HIV testing.

\section{Strengths and Limitations}

There are strengths and limitations to this research based on the selected study design and sampling. Disaggregating of data by focusing on one specific ethnic group is a strength of the design and essential to the advancement of the

API health research agenda. Some limitations are worth noting, however. Since this study uses a cross-sectional design, it is not possible to determine causality. For example, it is unknown whether reasons for testing were precursors or consequences of sexual activity. This was an exploratory study that required the use of a purposive and convenience sampling; therefore, the nonrandom sampling technique limits the generalizability of the results. Additionally, selfselection biased the results because a number of students were solicited to participate in the study while they were visiting their school health center. Such students, if they were visiting the student health center for reproductive or sexual health concerns, may conceivably have a higher level of HIV prevention awareness. Targeted outreach to high traffic areas throughout multiple campuses, however, helped decrease that bias. While the data gathered from the questionnaire were based on self-reports, which may threaten internal validity due to recall error, this was minimized by focusing on the last or more recent sexual relationship. Self-reports may have also been prone to social desirability bias, though, given the multitude of variables that were examined, this was unavoidable.

\section{Recommendations for Future Research}

This was an exploratory study designed to assess HIV testing rates and the complexity of factors that influences an important health screening decision, one that is uniquely stigmatized within the API community. More research is needed to evaluate strategies that may be effective in addressing constructs of the HBM model, such as raising the level of perceived susceptibility to HIV infection, raising the level of perceived benefits and reducing the level of perceived barriers of HIV testing among this population. Developing strategies on increasing self-efficacy of Chinese/Chinese American college women to seek testing is an area that also deserves further investigation. The roles of culture, ethnic 
identity, and acculturation also need to be further explored within the context of HIV prevention messages, and specifically for encouraging HIV testing for Chinese/Chinese American women.

\section{Acknowledgements}

This research study is part of a dissertation work supported by Loma Linda University, Center for
Health Research and Ohlone College Student Health Center. We wish to thank the directors of the participating student health centers for their support and the participants for their insights and assistance. Special thanks to the following individuals for their assistance with data collection and manuscript review: Jacob Chang, Verna Mae Salting, Wendy Trieu Sanchez, Katy Yen.

\section{References}

American College Health Association (2002). Healthy Campus 2010 Manual. Baltimore, MD: September 2002.

American College Health Association (2005). Standards of practice for health promotion in higher education. Baltimore, MD: American College Health Task Force on Health Promotion in Higher Education. Revised January 2005.

American College Health Association (2007). American College Health Association-National College Health Assessment: Reference Group. HSACCC Consortium Executive Summary. Spring 2007. Baltimore: American College Health Association.

Anastasi, M., Sawyer, R. G., \& Pinciaro, P.J. (1999). A descriptive analysis of students in seeking HIV antibody testing at a university health service. Journal of American College Health, 48, 13-20.

California Department of Health Services, Office of AIDS (2005). California HIV Counseling and Testing Annual Report. Available at: http://www.dhs.ca.gov/AIDS/.

Centers for Disease Control and Prevention (1999). HIV and its transmission. Available at http://www.cdc.gov/hiv/resources/factsheets/PDF/transmission.pdf

Centers for Disease Control and Prevention (2006). Racial/Ethnic disparities in diagnoses of HIV/AIDS - 33 States, 2001 - 2004, MMWR, 55, 1-17. Available at: http://www.cdc.gov/mmwr.

Chin, D. (1999). HIV-related sexual risk assessment among Asian/Pacific Islander American Women: An inductive model. Social Science \& Medicine, 49, 241-251.

Cooper, M., Loue, S., \& Lloyd, L.S. (2001). Perceived susceptibility to HIV infection among Asian and Pacific Islander women in San Diego. Journal of Health Care for the Poor \& Underserved, 12, 208-222.

Darbes, L.A., Kennedy, G.E., Peersman, G., Zohrabyan, L., \& Rutherford, G.W. (2002). Systematic review of HIV behavioral prevention research in Asian Americans and Pacific Islanders. UCSF Center for HIV Information HIV InSite. Available at http://hivinsite.ucsf.edu/.

DiClemente, R.J., Brown, L.K., Beausoleil, M.S., \& Ludico, M.A. (1993). Comparison of AIDS knowledge and HIV-related sexual behaviors among adolescents in low and high AIDS prevalence communities. Journal of Adolescent Health, 14, 231-236.

Estrada, A. \& Estrada, B. (2002). HIV/AIDS and Acculturation: Theoretical Foundation and Methodological Issues powerpoint presentation slides. Hawai'i AIDS Education and Training Center and AIDS Education Project. Available at: http://www.hawaii.edu/hivandaids/links_culture.htm

Flannery D. \& Ellingson, L. (2003). Sexual risk behaviors among first year college students, 2000-2002. Californian Journal of Health Promotion, 1, 93-104.

Glanz, K., Rimer, B.K., \& Lewis, F.M. (2002). Health behavior and health education: Theory, research, and practice ( $3^{\text {rd }}$ edition). San Francisco: Jossey-Bass.

Holtby, S., Zahnd, E., McCain, C., Chia, Y.J., \& Kurata, J.H. (2006). Health of California's Adults, Adolescents and Children: Findings from CHIS 2003 and CHIS 2001. Los Angeles, CA: UCLA Center for Health Policy Research. 
Hou, S. (2007). Alternative modes of measuring self-reports on HIV-related behaviors among college students: Web-delivered mode versus paper-pencil mode. American Journal of Health Education, 38, 9-15.

Inungu, J.N., Quist-Adade, C., Beach, E.M., Cook, T., \& Lamerato, M. (2005). Shift in the reasons why adults seek HIV testing in the United States: policy implications. AIDS Read, 15, 35-42.

Jemmott, L.S., Maula, E.C., \& Bush, E. (1999). Hearing our voices: assessing HIV Prevention needs among Asian and Pacific Islander women. Journal of Transcultural Nursing, 10, 102-111.

Kaiser Family Foundation (2006). HIV/AIDS policy fact sheet: HIV testing in the United States. September 2006. Available at http://www.kff.org/hivaids/index.cfm.

Kuo, W. \& St. Lawrence, J. (2006). Sexual behaviour and self-reported sexually transmitted diseases (STDs): Comparison between White and Chinese American young people. Culture, Health \& Sexuality, 8, 335-349.

Lam, A.G. \& Barnhart, J.E. (2006). It takes two: The role of partner ethnicity and age characteristics on condom negotiations of heterosexual Chinese and Filipina American college women. AIDS Education \& Prevention, 18, 68-80.

Lam, A.G., Mak, A., Lindsay, P.D., \& Russell, S.T. (2004). What really works? An exploratory study of condom negotiation strategies. AIDS Education \& Prevention, 16, 160-171.

Lee-Lin, F., Menon, U., Pett, M., Nail, L., Lee, S., Mooney, K. (2007). Breast cancer beliefs and mammography screening practices among Chinese American immigrants. Journal of Obstetric, Gynecological, and Neonatal Nursing, 36, 212-21.

Lin, P., Simoni, J.M., \& Zemon, V. (2005). The Health Belief Model, sexual behaviors, and HIV risk among Taiwanese immigrants. AIDS Education \& Prevention, 17, 469-483.

Lux, K. \& Petosa, R. (1994). Preventing HIV infection among juvenile delinquents: educational diagnosis using the health belief model. International Quarterly of Community Health Education, 15, 145-163.

Marelich, W.D. \& Clark, T. (2004). Human immunodeficiency virus (HIV) testing and false disclosures in heterosexual college students. Journal of American College Health, 53, 109-115.

Mattson, M. (2002). Impact of HIV test counseling on college students' sexual beliefs and behaviors. American Journal of Health Behavior, 26, 121-136.

Morrill, A.C. \& Noland, C. (2006). Interpersonal issues surrounding HIV counseling and testing, and the phenomenon of "testing by proxy." Journal of Health Communication, 11, 183-198.

Nguyen, T.Q., Ford, C.A., Kaufman, J.S., Leone, P.A., Suchindran, C., \& Miller, W.C. (2006). HIV Testing among young adults in the United States: Associations with financial resources and geography. American Journal of Public Health, 96, 1031-1034.

Opt, S. K. \& Loffredo, D.A. (2004). College students and HIV/AIDS: more insights on knowledge, testing and sexual practices. Journal of Psychology, 138, 389-402.

Rotheram-Borus, M.J., Murphy, D.A., Coleman, C.L., Kennedy, M., Reid, H.M., Cline, T.R., Birnbaum, J.M., Futterman, D., Levin, L., Schneir, A., Chabon, B., O'Keefe, Z., \& Kipke, M. (1997). Risk acts, health care, and medical adherence among HIV+ youths in care over time. AIDS and Behavior, 1, 43-52.

Shapiro, J., Radecki, S., Charchian, A.S., \& Josephson, V. (1999). Sexual behavior and AIDS-related knowledge among community college students in Orange County, California. Journal of Community Health, 24, 29-43.

So, D.W., Wong, F.Y., \& DeLeon, J. (2005). Sex, HIV risks, and substance use among Asian American college students. AIDS Education \& Prevention, 17, 457-468.

Steers, W.N., Elliot, E., Nemiro, J., Ditman, D., \& Oskamp, S. (1996). Health beliefs as Predictors of HIV-preventive behavior and ethnic differences in prediction. The Journal of Social Psychology, 136, 99-110.

Suinn, R.M. (1995). Suinn-Lew Asian Self-Identify Acculturation Scale (SL-ASIA). Permission for use of SL-ASIA scale granted by author January 11, 2007. Author website available at: http://psy.psych.colostate.edu/psylist/detail.asp?Num=54 
The Sexual Health of Asian American/Pacific Islander Young Women - Focus on Assets. Advocates for Youth. 2007

University of California, San Francisco, Center for AIDS Prevention (2003). What are Asian and Pacific Islander HIV prevention needs? Fact sheet. Accessed on March 1, 2006. Available at: http://www.caps.ucsf.edu/API.html

U.S. Census Bureau, Census 2000. We the People: Asians in the United States. Census 2000 Special Reports. Available at: http://www.census.gov/prod/2004pubs/censr-17.pdf

U.S. Department of Health and Human Services (2000). Healthy People 2010. 2nd ed. With understanding and improving health and objectives for improving health. 2 vols. Washington, DC: U.S. Government Printing Office, November 2000.

U.S. Department of Health and Human Services, Health Resources and Services Administration (2006). Women's Health USA 2006. Rockville, Maryland: U.S. Department of Health and Human Services, 2006.

Wang, C. \& Mallinckrodt, B. (2006). Acculturation, Attachment, and Psychosocial Adjustment of Chinese/Taiwanese International Students. Journal of Counseling Psychology, 53, 422b - 433.

Wenger, N.S., Linn, L.S., Epstein, M., \& Shapiro, M.F. (1991). Reduction of high-risk sexual behavior among heterosexuals undergoing HIV antibody testing: a randomized clinical trial. American Journal of Public Health, 81, 1580-1585.

Witte, K., McKeon, J., Cameron, K., \& Berkowitz, J. (1995). The Risk Behavior Diagnosis Scale manual. Department of Communication, Michigan State University, East Lansing, MI. Available at: http://www.msu.edu/ wittek/rbd.htm.

Wortley, P.M., Metler R.P., Hu, D.J., \& Fleming, P.L. (2000). AIDS among Asians and Pacific Islanders in the United States. American Journal of Preventive Medicine, 18, 208-214.

Yep, G.A. (1993). HIV prevention among Asian-American college students: does the Health Belief Model work? Journal of American College Health, 41, 199-205.

$\mathrm{Yu}, \mathrm{M} . \& \mathrm{Wu}, \mathrm{T}$. (2005). Factors influencing mammography screening of Chinese American women. Journal of Obstetric, Gynecological, and Neonatal Nursing, 34, 386-94.

Zaidi, I.F., Crepaz, N., Song, R., Wan, C.K., Lin, L.S., Hu, D.J., \& Sy, F.S. (2005). Epidemiology of HIV/AIDS among Asians and Pacific Islanders in the United States. AIDS Education \& Prevention, 17, 405-417. 
Author Information

Sang Leng Trieu, Dr.PH, MPH, CHES*

Loma Linda University, School of Public Health

Loma Linda, CA 92350

2010 S. Batson Ave. \#247

Rowland Heights, CA 91748

Phone: $213.694 .1250 \times 4467$

Fax: $\quad 213.438 .5744$

Email: sangleng@yahoo.com

Naomi N. Modeste, Dr.PH, CHES

Loma Linda University, School of Public Health Department Chair and Professor, Health Promotion and Education

Loma Linda, CA 92350

Helen Hopp Marshak, Ph.D, MS, CHES

Loma Linda University, School of Public Health Associate Professor, Health Promotion and Education Loma Linda, CA 92350

Michael A. Males, Ph.D

Senior Researcher, Center on Juvenile and Criminal Justice San Francisco, CA 94103

Sally I. Bratton, RN, FNP, PA-C

Ohlone College

Director, Student Health Center

Fremont, CA 94539

* corresponding author 


\section{Appendix A}

Table 1

Demographics and Sexual Behavior of Sample Population (N=230)

\begin{tabular}{|c|c|c|c|c|c|}
\hline Student Demographics & $\mathrm{N}$ & $\%$ & \multirow{2}{*}{$\begin{array}{l}\text { Sexual Behavior of Sample Population } \\
\text { Age of sexual debut }(\mathrm{N}=227 \\
\text { Mean=16.97) }\end{array}$} & $\mathrm{N}$ & $\%$ \\
\hline \multicolumn{3}{|l|}{ Age $(\mathrm{N}=230$, Mean $=20, \mathrm{SD}=1.89)$} & & & \\
\hline \multicolumn{2}{|l|}{$18-20$} & 68 & $13-15$ years old & 50 & 22 \\
\hline \multicolumn{2}{|l|}{$21-24$} & 32 & 16-18 years old & 132 & 58 \\
\hline \multicolumn{2}{|l|}{ Ethnicity $(\mathrm{N}=231)$} & & 19-21 years old & 42 & 19 \\
\hline \multicolumn{2}{|l|}{ Chinese/Chinese American } & 73 & $22-24$ years old & 3 & 1 \\
\hline Taiwanese/Taiwanese American & 35 & 15 & Partners in last year $(\mathrm{N}=220$, Mean $=1.3)$ & & \\
\hline Chinese mixed & 28 & 12 & None & 23 & 11 \\
\hline Place of birth $(\mathrm{N}=230)$ & & & 1 partner & 139 & 63 \\
\hline US & 128 & 56 & 2 partners & 42 & 19 \\
\hline China & 46 & 20 & 3 or more partners & 16 & 7 \\
\hline Hong Kong & 19 & 8 & $\begin{array}{l}\text { Condom use during last intercourse } \\
(\mathrm{N}=228)\end{array}$ & & \\
\hline Taiwan & 22 & 9 & Yes & 135 & 59 \\
\hline Other & 15 & 7 & No & 82 & 36 \\
\hline $\begin{array}{l}\text { Primary \& secondary education } \\
(\mathrm{N}=231)\end{array}$ & & & Don't remember & 11 & 5 \\
\hline US & 156 & 68 & History of STD $(\mathrm{N}=230)$ & & \\
\hline Abroad & 75 & 32 & No, never been tested & 126 & 55 \\
\hline Years in the US $(\mathrm{N}=231)$ & & & No, tested and negative & 93 & 40 \\
\hline Less than 2 years & 28 & 12 & Yes & 11 & 5 \\
\hline $2-5$ years & 43 & 19 & Method of contraception $(\mathrm{N}=229)$ & & \\
\hline $6-10$ years & 16 & 7 & No contraception used & 23 & 10 \\
\hline More than 10 years & 144 & 62 & Condoms & 129 & 56 \\
\hline International student $(\mathrm{N}=229)$ & & & Oral contraceptives & 51 & 22 \\
\hline Yes & 29 & 13 & Withdrawal & 11 & 5 \\
\hline No & 200 & 87 & Other & 15 & 7 \\
\hline Relationship status (N=231) & & & $\begin{array}{l}\text { Use of emergency contraception } \\
(\mathrm{N}=229)\end{array}$ & & \\
\hline $\begin{array}{l}\text { Single/Relationship with no sexual } \\
\text { activity }\end{array}$ & 43 & 19 & $x^{2}-1, \frac{1}{4}$ & 86 & 38 \\
\hline One casual partner & 42 & 18 & No & 143 & 62 \\
\hline One committed partner & 138 & 60 & & & \\
\hline Multiple partners & 8 & 3 & & & \\
\hline Length of relationship $(\mathrm{N}=231)$ & & & & & \\
\hline $1-5$ months & 77 & 34 & & & \\
\hline 6-12 months & 61 & 26 & & & \\
\hline Longer than a year & 93 & 40 & & & \\
\hline Ethnicity of current/former partner & $235)^{*}$ & & & & \\
\hline Chinese & 142 & 61 & & & \\
\hline Other Asian/Pacific Islanders & 72 & 31 & & & \\
\hline Non-Asians & 66 & 28 & & & \\
\hline
\end{tabular}

* Total \% exceeds $100 \%$, because respondents were allowed to check all that apply. 


\section{Appendix B}

Table 2.

Level of HIV Knowledge among Those Who Had Tested and Those Who Had Never Tested

\begin{tabular}{|c|c|c|c|c|c|}
\hline & & \multicolumn{3}{|c|}{$\%$} & \multirow[b]{2}{*}{$\mathrm{P}$ value } \\
\hline & Statement & Tested & $\begin{array}{l}\text { Never } \\
\text { Tested }\end{array}$ & Total & \\
\hline 1. & $\begin{array}{l}\text { A person can get AIDS from sharing needles to inject drugs } \\
(\mathrm{n}=230)\end{array}$ & 98.5 & 94.9 & 96.0 & 0.209 \\
\hline 2. & A person can get AIDS from using public toilet seats $(n=230)$ & 95.9 & 84.7 & 87.9 & $0.023 *$ \\
\hline 3. & A person can get AIDS from donating blood $(n=229)$ & 49.3 & 34.0 & 38.6 & $0.032 *$ \\
\hline 4. & $\begin{array}{l}\text { A person can get AIDS from having sex without using a } \\
\text { condom }(n=230)\end{array}$ & 97.0 & 95.5 & 96.0 & 0.607 \\
\hline 5. & A person can get AIDS from having a blood test $(n=230)$ & 64.2 & 61.1 & 62.1 & 0.668 \\
\hline 6. & $\begin{array}{l}\text { A person can get AIDS from holding hands with someone } \\
(\mathrm{n}=227)\end{array}$ & 100.0 & 98.1 & 98.6 & 0.250 \\
\hline 7. & $\begin{array}{l}\text { People can reduce their chances of becoming infected with } \\
\text { the AIDS virus by not having any kind of sexual intercourse } \\
\text { with an IV drug user }(n=229)\end{array}$ & 91.0 & 79.5 & 81.2 & 0.328 \\
\hline 8. & $\begin{array}{l}\text { Anyone who has the AIDS virus can infect someone else } \\
\text { during sexual intercourse }(n=230)\end{array}$ & 98.5 & 94.3 & 95.5 & 0.159 \\
\hline 9. & $\begin{array}{l}\text { A pregnant woman who has the AIDS virus can infect her } \\
\text { unborn baby }(n=224)\end{array}$ & 91.0 & 93.0 & 92.4 & 0.614 \\
\hline 10. & There is a cure for AIDS $(n=224)$ & 94.0 & 87.9 & 89.7 & 0.166 \\
\hline 11. & Only gay men get AIDS $(n=221)$ & 97.0 & 98.1 & 97.7 & 0.616 \\
\hline 12. & $\begin{array}{l}\text { People can reduce their chances of becoming infected with } \\
\text { the AIDS virus by not having any kind of sexual intercourse } \\
\text { (being abstinent) }(n=222)\end{array}$ & 91.0 & 80.0 & 83.3 & $0.043 *$ \\
\hline \multirow[t]{2}{*}{13.} & $\begin{array}{l}\text { A person can get AIDS from being bitten by } \\
\text { mosquitoes/insects }(n=220)\end{array}$ & 89.2 & 68.4 & 74.5 & $0.010^{*}$ \\
\hline & Total Mean & 88.2 & 81.8 & 83.4 & $0.001 * *$ \\
\hline
\end{tabular}

